\title{
A Study on the Contemporary Turn of Feminist-Oriented Social Work Theory and Its Influence
}

\author{
Chenming Zhang \\ Institute of Political and Law, University of Chinese Academy of Social Sciences, Beijing, China \\ Email: amzhang1@163.com
}

How to cite this paper: Zhang, C. M. (2019). A Study on the Contemporary Turn of Feminist-Oriented Social Work Theory and Its Influence. Advances in Applied Sociology, 9, 79-85.

https://doi.org/10.4236/aasoci.2019.92007

Received: January 11, 2019

Accepted: January 30, 2019

Published: February 2, 2019

Copyright $\odot 2019$ by author(s) and Scientific Research Publishing Inc. This work is licensed under the Creative Commons Attribution International License (CC BY 4.0).

http://creativecommons.org/licenses/by/4.0/

\section{(c) (7) Open Access}

\begin{abstract}
The thought and practice of feminist-oriented social work came from the women's liberation movement in the 1960s. During the following decades, a large number of feminist-based social work theories emerged, which guided the practice of the social work counteractively. Generally speaking, the development of feminist-oriented social work theory has gone through three stages: germination-development-contemporary turn. This paper mainly studies the contemporary turn of feminism in social work theory and the influence of feminism on social work from the perspective of traditional social work theory, which is aimed to provide reference for the protection of contemporary women's rights.
\end{abstract}

\section{Keywords}

Feminism, Social Work, Gender, Women's Rights, Contemporary Turn

\section{Introduction}

The development of feminist-oriented social work opens a new door for all walks of life, especially for contemporary women. It describes to women a brand-new and gender-oriented world, in which women are no longer ashamed to express their own demands, no longer take patriarchal oppression for granted, and they can choose to seek help when they encounter unfair treatment. In this process, social work has also realized the transformation from superficial level to deepness, from initial stage to maturity. Feminist-related social work is no longer confined to the expression of radical demands, but more in practice attempts to break the silence, namelessness and powerlessness of the weak and regain the subjectivity of self-expression. 


\section{Traditional Social Work Theory}

\subsection{The Development History and Construction of Social Work Theory}

Social work is regarded as a discipline aiming at solving social problems by helping people featured by taking altruism as its basic principle and social welfare and social insurance as basic content with strong practical characteristics. Therefore, the theoretical research of social work has always been considered to lag behind the practice of social work. In 1917, Mary Richmond, an American philanthropist, published the book Social Diagnosis, which systematically summarized the practical results of social work at that time and put forward the general theory of social work (Debora, 2004). The publication of this book is highlighted to be the beginning of the theoretical study of social work. Since then, social work began to move from a practical work to a professional and standardized direction.

In Social Diagnosis, the author includes a series of social work-related disciplines, such as psychology, sociology and natural science into the scope of research. Conforming to the comprehensive characteristics of social work, the book points out a new direction for the theoretical research of social work, but this creative progress has also brought some problems. In the following decades, the theoretical research field of social work showed a mixed situation of various disciplines. The research work was slightly weak due to the lack of study specifically for social work. This phenomenon has not been alleviated until the past 30 years.

Social work theory was originally born in medical research. In the long-term development, it gradually integrated the theories of other disciplines and formed the characteristics of people-oriented and highly humanistic feelings. Humanistic feelings have become an indispensable part of social work theory. With the continuous development of social work practice, the theoretical research is required to play a scientific guiding role. The results of research should enhance the operability of social work practice. Therefore, scientific nature has become one of the principles that the theoretical research of social work needs to follow (Rogers, 2006). As we all know, social work plays an important role in the whole society, especially in safeguarding human rights and maintaining social equality, so social work itself is endowed with political characteristics and it does not exclude the existence of politics. However, in the construction of social work theory, more emphasis is placed on "life politics", which is somewhat different from the traditional political viewpoint.

\subsection{Feminism's Criticism of Traditional Social Work Theory}

Feminism holds that the contemporary society is based on the dominance of men. In response, in all aspects of social life, there are inequalities caused by gender differences, mainly in the fields of workplace, salary, marriage, education, reproduction and so on. Therefore, feminism advocates solving the problem of 
inequality between men and women through efforts. Since the 1980s, feminism has been recognized by more and more people, and has set off a wave in various regions, strata and fields. Because of its own nature, the field of social work is also deeply influenced by feminism (Stohr, 2015).

Feminism criticizes the traditional theory of social work, mainly in the following three points. Firstly, feminism argues that the traditional social work theory is still based on patriarchal doctrine with male rights as its starting point, and its implicit principles serve men. The research on the close relationship with women's vital interests, such as reproduction and marriage that is not deep enough and even unconsciously weakens women's status in social work. Moreover, in the view of feminism, patriarchy exerts a subtle influence on social work theory. Although it does not indicate that male power is higher than female power apparently, under the background of the differences between men and women, traditional social work theory causes actual inequality.

Secondly, feminism questions the sample study in social work research. In the current social work research, there is a phenomenon, that is, for the general social work research, the sample object is mainly male and the number of male samples occupies the majority of the research object, while the number of women is very small or even no, and the proportion of men and women is not coordinated. Only in those social work studies involving women's issues will women be the main research objective. It is obviously unreasonable that the research results with women as the research objective only apply to the social work level of women, while those with men as the research objective can be applied to the general environment of human society (Calkin, 2015). In addition, feminism holds that there are differences between men and women in all aspects of physiology and psychology. Therefore, many social studies based on male groups can not be directly applied to women's social work.

Thirdly, feminism pays more attention to the function of mothers, which is seldom mentioned in traditional social work theory. Because of their special physiological structure, women are born with the responsibility of human reproduction, which is the implicit requirement of society for women. However, feminism holds that under the premise of the increasing number of professional women, the existence of this implicit requirement is the oppression of women. Women's reproductive rights are not guaranteed. In real life, women are often limited by the "glass ceiling". Traditional social work seems to be a smooth way for women, but it is not the way in reality.

\section{Research on the Theory of Feminist-Oriented Social Work and Its Contemporary Turn}

\subsection{Research on the Theory of Feminist-Oriented Social Work}

In 1791, Olympe de Gouges, a famous French feminist leader, published the world's first declaration calling for equality between men and women. She proposed that more attention should be paid to the role of women in social devel- 
opment and efforts should be made in both work and family to realize gender equality. Since then, the pursuit of equality between men and women has been fixed as the feminist principle. With the gradual development of the past feminism into the contemporary feminism, many researchers have discussed feminism from various aspects in the past 100 years. In the 1960s, feminist-oriented social work was burgeoning (Kellian, 2015). At that time, many women helped each other in the community life, and this relationship gradually developed into feminist-oriented social work. They no longer shy away from the dilemma brought about by their female identity, but face it actively, are brave enough to point out the crux of the problem, and assist some oppressed women to regain their identity confidence. It can be said that the theory of feminist-oriented social work was born from the practice of women's mutual assistance. From the very beginning, it has the characteristics of practicality, and also has a more practical understanding of women social identity. After the 1980s, the theory of feminist-oriented social work was born formally.

Barbara. G. Collins (1986), a sociologist, pointed out in her research that social work inherently has the features of feminist, and the development of feminism and deepening of social work will make the two things inevitably meet. The altruism of social work makes the theoretical research of social work focus more on the vulnerable groups in the society. Women are more likely to be vulnerable groups due to physical insufficiency and actual gender discrimination in society. Therefore, it is natural for social work to pay attention to women's rights. In social work, women are a kind of social identity, and their original status is questioned. The theory of social work concentrates on the reasons for gender difference and identity difference between men and women, and intends to break the bondage of female identity through the practice of social work.

The researches of feminist-oriented social work have experienced three development stages. The first stage is the embryonic stage from the 1960s to the early 1980s. In this stage, the combination of feminism and social work was spontaneous, and they mainly existed in the field of community work with the main form of women's mutual assistance. The second stage is the construction stage of social identity based on female gender. From the time when the theory of feminist-oriented social work was put forward in 1980s to the mid-1990s, women as a whole were mentioned in the feminist-oriented social work. The third stage is from the mid-1990s to the present, which is the turning period of the feminist-oriented social work. In this stage, we paid attention to the protection of women's individual rights and interests, and emphasized that the theoretical researches of feminist-oriented social work should focus on the promotion of women's right of speech.

\subsection{The Contemporary Turn of Theory of Feminist-Oriented Social Work}

Through the above researches, we find that the theory of feminist-oriented social work has noticed the gender issues caused by women social identity and made 
attempts to solve them. Generally speaking, the theory of feminist-oriented social work underlines the reconstruction of women's status based on women social identity, hoping to solve social problems by raising the social status of vulnerable groups. At the same time, this practice also has some shortcomings. People's social identity is complex and changing. The roles and statuses of both male and female in society are relative. Perhaps in some circumstances, women exist as vulnerable groups, but in another, they may suddenly change their identity and become a synonym of political correctness. The use of feminism by politicians actually reinforces the solidification of women social identity, and artificially creates misunderstandings based on gender differences.

Therefore, in the contemporary society, researches of social work theory have gradually turned from the direction based on women social identity to the improvement of women's right of speech, so as to enhance women's right of speech and enable women to express their own demands. The social work theory based on women's right of speech stresses the independent pursuit of women as individuals. Compared with regarding women as a whole, it can better reflect the people-oriented working principle of social work, and reduce the social power backlash caused by the construction of women social identity, which is beneficial to women's own development.

The change from monism to pluralism and from closure to openness is the main characteristics of the shift of feminist-oriented social work in modern society. The theory of feminist-oriented social work in the $1980 \mathrm{~s}$ emphasized that women as a whole should enjoy a series of social rights based on female identity as a social identity, and ignored the differences between individuals and lacked operability. However, the contemporary feminist-oriented social work theory independently treats every woman who receives help. It not only recognizes the development dilemma presented by women's social status, but also considers the actual difficulties encountered by each individual, adjusts the strategies of social work based on the actual situation, and optimizes the results of social work. We go deep into the female group and change our way of solving problem, considering from the concept that "how men view women" to the idea that "how women view women", and put forward solutions to women's concerns.

The contemporary shift in feminist-oriented social work also includes a shift from attaching importance to the results to attaching importance to the processes. It was originally hoped that through the combination of the feminism and social work, the leap of women's status can be directly achieved, the equal rights of different genders can be realized, and the social status of women can be improved. However, the influence of patriarchalism formed in the thousands of years of development of human society is extremely far-reaching, and it is impossible for feminism to achieve the desired result in just a few decades. Therefore, the ideas which are hard to realize have been changed in contemporary feminism. It has changed from the pursuit of theoretical equal rights, political equality, etc., to the pursuit of the solution to the dilemma faced by women in reality, finally achieving gender equality through the protection of every woman's 
rights. In fact, it also adapts to the practicability of the social work itself for the feminism to pay more attention to the processes of social work. Naturally, social work has the characteristics of inadequate theoretical development and extremely wide scope of practice. Therefore, the choice of feminism to reduce theoretical research and pay more attention to the practical process is the one that is most suitable for the rhythm of social work. In this context, the adaptability between feminism and social work can be rapidly improved, which is naturally more conducive to the development of theoretical research.

\section{The Impact of Feminism on Social Work}

The feminist movement has promoted the development of theoretical research on social work. The feminist movement has forced social workers and social service systems to respond to the construction of women's social identity and gender issues, and inspired some social workers to think about feminism. At the same time, researchers have begun to pay attention to issues about the combination of women's social identity and social work. While women's identity is valued, it has also brought about a feminist-oriented social work critique and a feminist-oriented social work model that are compatible with the feminist theory. This is a way of thinking that is different from traditional social work theory, emphasizing that when there are social problems, people can think about the issues and find ways to solve problems from the perspective of feminism. This transformation, which helps women to resist the domination of strong power over women's identity in practice, is a sign indicating that the social work theory is maturing. In practice, we can find that although many social workers have not explicitly claimed that they are supporters of feminism, they can respond to many female issues such as sexual violence, sexual crimes, marital problems, and fertility issues from a feminist point of view that advocates equality between men and women in their work (Tate, 2013).

Feminist-oriented social work theory has important significance in reshaping the theoretical connotation for both the feminism itself and the social work related research. In this field, gender is no longer an unfavorable factor affecting women's social identity. In the social work theory, the link between gender and rights is pointed out, and the realization of gender equality is taken as the goal, which has resulted in a leap in theoretical research. Feminism offers another possibility to the study of social work. If the feminist-oriented social work is a combination of feminism and social work, then this "combination" undoubtedly benefits from the critical transformation of feminist on traditional social work. It is precisely the professional innovation brought by feminism that comprehensively promotes the combination of feminism and social work and subsequently affects the theoretical characteristics and practical character of social work.

\section{Conclusion}

In summary, this paper studies the contemporary shift and influence of femin- 
ist-oriented social work. Feminism is born out of social changes, and social work comes from the practice of altruism. The urgent need to solve realistic problems has brought feminism and social work together. The feminist-oriented social work theory was originally focused on the reconstruction of women's social identity. With the development of practice, this attempt was gradually replaced by a more personalized feminist-oriented social work theory based on the promotion of discourse power, realizing the contemporary shift of the feminist society work. The combination of feminism and social work has many positive effects. From then on, feminism has moved from theoretical research to more extensive practice, which has promoted the development of contemporary protection of women's rights and interests, and social work has also had new connotations and development directions, and is gradually maturing under the guidance of correct theories.

\section{Conflicts of Interest}

The authors declare no conflicts of interest regarding the publication of this paper.

\section{References}

Calkin, S. (2015). Feminism, Interrupted? Gender and Development in the Era of "Smart Economics". Progress in Development Studies, 15, 295-307. https://doi.org/10.1177/1464993415592737

Debora, H. (2004). Shulamith Firestone: Radical Feminism and Visions of the Information Society. Information Communication and Society, 7, 115-135. https://doi.org/10.1080/1369118042000208933

Kellian, C. (2015). Psychology's Feminist Voices. Reference Reviews, 29, 341-354.

Rogers, W. A. (2006). Feminism and Public Health Ethics. Journal of Medical Ethics, 32, 351-354. https://doi.org/10.1136/jme.2005.013466

Stohr, R. A. (2015). Transnational Feminism, Global Governance, and the Reimagination of the Organization-Society Relationship: A Case Study of the Women's Environment and Development Organization. Communication Theory, 25, 208-229. https://doi.org/10.1111/comt.12063

Tate, C. C. (2013). Addressing Conceptual Confusions about Evolutionary Theorizing: How and Why Evolutionary Psychology and Feminism Do Not Oppose Each Other. Sex Roles, 69, 491-502. https://doi.org/10.1007/s11199-012-0226-3 